\title{
Formação continuada de diretores escolares: uma experiência fundamentada na pesquisa ação colaborativa ${ }^{1}$
}

\author{
The continuous training of school directors: \\ an experience based on collaborative action research \\ Formación continua de directores de escuela: \\ una experiencia con bases en la formación - acción colaborativa
}

\author{
YOSHIE USSAMI FERRARI LEITE \\ VANDA MOREIRA MACHADO LIMA
}

\begin{abstract}
Resumo: O artigo resulta de pesquisa coletiva e visa refletir uma ação de formação continuada com diretores fundamentada na pesquisa ação colaborativa. Partiu da análise das representações sociais desses sujeitos sobre seu papel e suas dificuldades, coletadas por questionário. A ação de formação ocorreu em encontros mensais, por dois anos, privilegiando a voz dos diretores, suas dificuldades, seus saberes e suas práticas. Constatamos avaliação positiva da ação empreendida por priorizar reflexões do cotidiano escolar, da gestão educacional e do papel desses profissionais por uma escola de qualidade.
\end{abstract}

Palavras chave: Formação continuada de diretores; escola pública estadual; pesquisa ação colaborativa.

\begin{abstract}
The current paper results from a collective research and aims to reflect on the continuous training of school directors based on collaborative action research. It started from the analysis of the social representations of these subjects regarding their role and their difficulties. Such data were collected by means of a questionnaire. The training action was held in monthly meetings, during two years, and it focused on the directors' "voice", difficulties, knowledge and practices. The action was positively evaluated because it prioritized reflections on the school's everyday life, education management and on the role played by these professionals in the struggle for a quality school.
\end{abstract}

Keywords: Continuing training of directors; state public school; collaborative research action.

Resumen: Este artículo es el resultado de una investigación colectiva y pretende reflexionar sobre una acción de educación continua de los directores con base en la investigación-acción colaborativa. Tomó como punto de partida el análisis de las representaciones sociales de estos sujetos sobre su papel y sus dificultades,

\footnotetext{
${ }^{1}$ Participaram desta pesquisa coletiva os autores deste artigo e outros pesquisadores da Faculdade de Ciências e Tecnologia (FCT/UNESP), docentes: Cinthia M.F. Ariosi, Cristiano A.G. Di Diorgi; Maria Suzana S. Menin; Silvio N. Militão; alunos da pós-graduação: Andréia Militão; Célia Aparecida Bettiol; Fabio Perboni; João Ferreiro Filho, Juliana A. M. Zechi, , Pamela T. B. Fernandes e Patrícia C.Azevedo.
} 
recogidas mediante un cuestionario. La acción formativa ocurrió en reuniones mensuales por dos años, centrándose en la voz de los directores, sus dificultades, sus conocimientos y sus prácticas. Encontramos valoración positiva de las medidas adoptadas, dando prioridad a las reflexiones de la vida escolar cotidiana, la gestión educacional y el papel de estos profesionales para una escuela de calidad.

Palabras clave: Educación continua de directores; escuela pública del estado; investigación acción colaborativa.

\section{INTRODUÇÃO}

Nas últimas décadas, o ensino público no Brasil tem se modificado significativamente. Houve a transformação de uma escola excludente e elitizada em uma instituição democrática que se abriu a todos os setores da população, em especial, às classes populares cujo acesso à escola não era então comum. Segundo Beisiegel (2006), a democratização da escola pública foi uma consequência de reivindicações das "massas populares urbanas". Em decorrência desses acontecimentos, o perfil do alunado também mudou, no entanto, essa mudança não foi acompanhada das adequações administrativas e pedagógicas necessárias para a organização dessa nova escola, condições essenciais para a conquista de um ensino de qualidade.

Se os alunos, cada um no seu ritmo, conseguem aprender continuamente, sem retrocessos, a escola é sábia e respeitosa. Se suas crianças e jovens são frequentadores assíduos das aulas, seguros de sua capacidade de aprender e interessados em resolver os problemas que os professores lhes impõem, ela está cumprindo o papel de torná-los pessoas autônomas, capazes de aprender pela vida toda. Se os alunos estão sabendo ouvir, discordar, discutir, defender seus valores, respeitar a opinião alheia e chegar a consensos, ela pode se orgulhar de estar formando cidadãos. E mais que tudo, se ela conseguir oferecer uma educação de boa qualidade a todos os seus alunos, independentemente de sua origem social, raça, credo ou aparência, certamente é uma escola de sucesso. (DAVIS, GROSBAUM, 2002, p. 77).

Considerando o contexto educacional complexo da atualidade, que devido ao acúmulo de atribuições transferidas hoje a escola, podemos dizer que as mudanças necessárias só acontecerão se tivermos como ponto de partida uma boa formação dos profissionais que nela atuam, incluindo entre eles os gestores (diretores, vice diretores e professores coordenadores).

Sabemos que a identidade e a atuação dos gestores das instituições também são essenciais no âmbito dessa escola democratizada, complexa e necessária. Entendemos ser papel desses profissionais decidir sobre problemas e dilemas da organização escolar, integrando os membros da equipe escolar num 
processo de análise e reflexão, em busca de soluções para os desafios com que se deparam em seu trabalho cotidiano. Para Davis e Grosbaum $(2002$, p. 88) a “organização da escola, é indispensável para promover o desenvolvimento e a aprendizagem dos alunos, implica um compromisso dos membros da equipe escolar com a clientela que frequenta a escola".

Há diferentes posições que se consolidaram historicamente sobre como deve ser a administração escolar. É possível sistematiza-la em dois grandes blocos: de um lado, a concepção de que a administração é um ato político e envolve a luta pelo direito à educação e à cidadania; de outro, a visão de que se trata de uma atividade técnica que, por isso, teria como aspecto central os conhecimentos específicos de sua prática. Essa discussão remonta à própria criação de uma área de estudo voltada à administração escolar, conforme destacado por Ribeiro (1968) ao aproxima-la da administração das organizações produtivas.

Silva Júnior (1990) destaca a pertinência desse debate que, embora se atualize constantemente, mantém a tensão original entre os polos opostos.

Como se pode perceber, a discussão sobre o trabalho do diretor de escola não privilegia seu aspecto essencial: a finalidade pedagógica de sua ação. $\mathrm{O}$ vínculo necessário ensino/administração é deixado de lado em ambos os pólos do debate. No pólo "teórico-técnico", a busca da identidade própria da administração escolar tende a aproximá-la muito mais da "administração" do que do "escolar", ou seja, o fato administrativo apresenta-se como substantivo e o fato pedagógico apenas como contingente. [...] No pólo "prático-político" o que se contempla é o postulado do "poder" do diretor e o que se busca é influenciar ou dominar o processo de investidura nesse poder [...] Em um e outro caso a qualidade do processo de ensino apenas se coloca como uma convenção subjacente. De um lado espera-se que ela aconteça como decorrência da tranquilidade assegurada por uma "administração competente". De outro, imagina-se que ela acontecerá como fruto da "autonomia" de uma escola protegida das injunções políticopartidárias. (SILVA JUNIOR, 1990, p. 65)

Dessa forma, nosso foco de pesquisa foi o diretor escolar.

Tendo em vista a recorrência de modelos/processos formativos destinados aos diretores que não consideram seus saberes e práticas, iniciamos a investigação, intitulada "Desenvolvimento Profissional do Gestor Escolar na Perspectiva da Pesquisa Ação: das representações à reorganização escolar", associada ao Centro Internacional de Estudos em Representações Sociais e Subjetividade - Educação, sediado na Fundação Carlos Chagas/SP, com a finalidade de aprimorar a formação continuada dos diretores das escolas públicas do Estado de São Paulo pertencentes à Diretoria de Ensino de Presidente Prudente (DE/PP), localizado no interior do estado. 
A pesquisa se insere na abordagem qualitativa e teve como ponto de partida a análise das representações sociais dos diretores sobre seu papel e as dificuldades encontradas no desempenho de suas funções. A primeira fase do estudo, iniciada em 2012, consistiu na aplicação de questionários a 35 diretores que atuam na $\mathrm{DE} / \mathrm{PP}$, o que representa $65 \%$ do total da população pesquisada. A segunda fase iniciou em 2013, quando realizamos, junto aos sujeitos pesquisados, a socialização e discussão dos dados empíricos coletados e começamos com as primeiras atividades de formação continuada voltada aos diretores da DE/PP que desejaram participar do projeto.

Escolhemos a pesquisa ação como metodologia neste processo de formação continuada por seu reconhecido impacto na formação do educador e na formulação de políticas públicas para a educação. Como aponta Pimenta (2005, p. 523), a pesquisa ação

[...] tem por pressuposto que os sujeitos que nela se envolvem compõem um grupo com objetivos e metas comuns, interessados em um problema que emerge num dado contexto no qual atuam desempenhando papéis diversos: pesquisadores universitários e pesquisadores (professores no caso escolar). Constatado o problema, o papel do pesquisador universitário consiste em ajudar o grupo a problematizá-lo; ou seja, a situá-lo em um contexto teórico mais amplo e assim possibilitar a ampliação da consciência dos envolvidos, com vistas a planejar as formas de transformações das ações dos sujeitos e das práticas institucionais.

Para a categorização e apreciação das questões abertas, recorremos à técnica da análise de conteúdo baseado em Franco (2008). Segundo essa autora elaboram-se as categorias a partir da análise da resposta escrita no questionário. $\mathrm{Na}$ elaboração das categorias, Franco (2008) apresenta dois caminhos: categorias criadas a priori: categorias e seus respectivos indicadores são predeterminados em função da busca a uma resposta específica do investigador. E categorias não definidas a priori que "emergem da fala, do discurso, do conteúdo das respostas e implicam constante ida e volta do material de análise à teoria" (FRANCO, 2008, p.53). Essa opção possibilita encontrar dados novos e diversificados. Nesta pesquisa optamos por trilhar esse último caminho.

Neste texto, priorizamos apresentar o perfil dos diretores da DE/PP, sujeitos da pesquisa, e descrever e analisar, a partir da "voz" desses profissionais, o que pensam sobre seu papel, suas dificuldades, suas concepções sobre a gestão democrática na escola pública estadual e suas vivências na ação de formação continuada desenvolvida no período de 2013 a 2014, fundamentada, portanto, na pesquisa ação colaborativa. 


\section{PERFIL DOS DIRETORES}

Constatamos que os sujeitos pesquisados atuam em oito municípios da região oeste do Estado de São Paulo, sendo vinte diretores de Presidente Prudente $(57 \%)$, três de cada um dos municípios de Martinópolis, Pirapozinho e Regente Feijó e mais quatro de escolas das cidades de Álvares Machado, Anhumas, Indiana e Taciba. Dois diretores não informaram os municípios onde atuam.

A maioria dos diretores $(72 \%)$ atua em instituições escolares onde são oferecidos o Ciclo II do Ensino Fundamental e o Ensino Médio; 14\% trabalham em escolas que, além desses níveis, oferecem também a Educação de Jovens e Adultos; 5,7\% atuam em instituições apenas com o Ciclo II do Ensino Fundamental; e 5,7\%, somente com o Ensino Médio.

Quanto à situação funcional, 69\% exercem o cargo de diretor e 31\%, a função de vice-diretor. Do total, $54 \%$ são efetivos e os demais substitutos ou designados.

As mulheres predominam, com um índice de $86 \%$, que corresponde a trinta sujeitos. Esse dado confirma o processo de feminilização do magistério, já apontado por vários estudos, como os realizados por Assunção (1996), Carvalho (1999), Tanuri (2000) e Pimenta (2002). Queremos crer que este dado possa representar, de fato, uma conquista profissional das mulheres, mais do que, propriamente, um símbolo de desvalorização social, decorrente da representação do trabalho feminino no imaginário social.

No que concerne à idade, os diretores estão na faixa entre 31 e 66 anos, sendo que $63 \%$ dos pesquisados têm mais de 51 anos, caracterizando, portanto, uma população profissionalmente mais experiente. Com relação ao estado civil, $80 \%$ são casados $11 \%$ separados e/ ou divorciados e $9 \%$ solteiros.

Quanto ao grau de escolaridade dos pais dos diretores participantes da pesquisa, $6 \%$ não possuem nenhuma escolaridade, 54\% cursaram da $1^{\mathrm{a}}$ à $4^{\mathrm{a}}$ série do Ensino Fundamental e 14\% frequentaram da $5^{\text {a à }} 8^{a}$ série. Portanto, $74 \%$ dos pais não chegaram a cursar o que, atualmente, se denomina Ensino Médio e somente 14\% possuem formação em nível superior. A escolaridade da maioria das mães, por sua vez, também não chegou a atingir o Ensino Médio (63\%), sendo que: $9 \%$ não estudaram, $48 \%$ cursaram o primeiro ciclo do Ensino Fundamental e $6 \%$ frequentaram da $5^{a}$ à $8^{a}$ série. Entre as mães com curso superior completo (14\%), três possuem ainda curso de especialização. O baixo grau de escolaridade dos pais dos diretores é, certamente, resultado do tardio processo de democratização do acesso à educação no Brasil, privilégio de uma favorecida e elitizada minoria, como nos aponta a história da educação brasileira. 
O grau de escolaridade do cônjuge dos diretores pesquisados é o que se mostra mais elevado. Pelos números, é possível constatar que estes apresentam maior formação escolar: 61\% possuem escolarização igual ou acima do Ensino Médio completo. Merece friso o fato de, do total de cônjuges, $20 \%$ possuírem Ensino Superior completo, $6 \%$ especialização e $6 \%$ mestrado.

Um dado interessante em relação à formação profissional é que, para a maioria dos profissionais investigados, o primeiro curso concluído não foi o de Pedagogia, uma vez que a soma das diversas licenciaturas atinge 88,6\% e este último apenas $11,4 \%$. Na segunda graduação apontada pelos diretores essa situação se inverte. Um índice de $71,4 \%$ cursou Pedagogia e somente 14,3\% frequentaram outros cursos de licenciatura (8,6\%, Geografia; 2,9\%, Filosofia; 2,9\%, Matemática).

Chama a atenção, também, o fato de que $65,7 \%$ dos diretores cursaram a primeira licenciatura em instituições privadas, enquanto $28,6 \%$ estudaram em universidades estaduais e $2,9 \%$ em instituição municipal. Com relação à modalidade da licenciatura, $77,1 \%$ frequentaram cursos presenciais e apenas $2,9 \%$ cursos de caráter semipresencial. Já em relação à segunda licenciatura, o índice da modalidade presencial cai para 54,3\%, seguido de 5,7\% da semipresencial e 2,9\% de cursos à distância.

A formação dos gestores em nível de pós-graduação apresenta um total de $65,7 \%$, sendo que $62,9 \%$ deles concluíram seus estudos após o ano de 2000 , dados passíveis de comprovar o movimento recente de incentivo institucional à formação continuada dos gestores. Em síntese, podemos afirmar que 82\% dos diretores pesquisados na DE/PP apresentam formação em curso de Pedagogia, sendo que para $11,4 \%$ deles esse curso foi a primeira licenciatura. Como segunda licenciatura, o percentual atingido foi de $71,4 \%$.

\section{O QUE PENSAM OS DIRETORES SOBRE SEU PAPEL}

A estrutura organizativa das escolas da rede estadual de São Paulo comporta um diretor, um vice diretor e um coordenador pedagógico que juntos compõem o denominado "trio gestor" ou "equipe gestora". Este quadro pode ser ampliado e ajustado em função do tamanho e do perfil da escola.

Indagados sobre o papel que desempenham, nas unidades escolares os diretores envolvidos na pesquisa apresentaram 54 respostas, que resultaram nas seguintes categorias: mediador de conflitos (18,5\%); orientador da equipe e das ações da escola (16,6\%); papel de muita responsabilidade e importância na escola (16,6\%); administrador da escola (14,8\%); líder (7,5\%); sobrecarregado (3,8\%); outros - psicólogo, médico, porto seguro, organizador, coordenador, 
prestador de contas, papel amplo, autoritário, formador, conscientizador, agente transformador, papel de fazer a diferença - (20,3\%); e "em branco" (1,9\%).

A compreensão do papel do diretor como "mediador de conflitos" no contexto escolar pode ser exemplificada pela escrita do Sujeito 25 que afirma "Hoje vejo meu papel como mediador, devido às diversidades. Todos os dias temos conflitos entre alunos, professores e funcionários".

Logo em seguida, com 16,6\%, aparece a categoria "orientador da equipe escolar e das ações na escola". Conforme apontado pelo sujeito 10: "O diretor hoje é alguém que procura com bom senso e paciência orientar todos os segmentos da escola ficando por último o pedagógico, que se ele não estiver junto do professor coordenador também pouco é produzido". Também com 16,6\%, as respostas que compõem a categoria "de muita responsabilidade e importância na escola" revelam que os diretores compreendem o encargo de sua função, como demonstra a reflexão feita pelo sujeito 7: "Papel de grande responsabilidade para quem dirige a instituição.".

A Resolução SE no 70, de 26 de outubro de 2010 (SÃO PAULO, 2010), que normatiza o perfil desejado para os profissionais da educação, descreve as competências e habilidades requeridas para o provimento dos diferentes cargos que compõem o quadro do magistério. O diretor escolar é "o profissional que se ocupa da direção, administração, supervisão e coordenação da educação na escola. Sua principal função é gerenciar todo o processo educativo da escola" (SÃO PAULO, 2010, online). Dentre as atribuições gerais compete ao diretor escolar,

[...] garantir, a concretização da função social da escola, liderando o processo de construção de identidade de sua instituição, por meio de uma eficiente gestão, nas seguintes dimensões: de resultados educacionais do ensino e da aprendizagem; participativa; pedagógica; dos recursos humanos; dos recursos físicos e financeiros. (SÃO PAULO, 2010, online).

A Resolução SE no 52, de 14 de agosto de 2013 (SÃO PAULO, 2013), que dispõe sobre os perfis, competências e habilidades requeridos dos profissionais da Educação da rede estadual de ensino, que estabelece de modo mais detalhado sobre o perfil do diretor de escola, caracterizando- o

Como dirigente e coordenador do processo educativo no âmbito da escola, compete ao Diretor promover ações direcionadas à coerência e consistência de um projeto pedagógico centrado na formação integral dos alunos [...] cabe-lhe uma atuação orientada pela concepção de gestão democrática e participativa, o que requer compreensão do contexto em que a educação é construída e a promoção de ações no sentido de assegurar o direito à educação para todos os alunos e expressar uma visão articuladora e integradora dos vários setores: pedagógico, curricular, administrativo, de serviços, das relações com a comunidade. Compete 
[...] ao Diretor de Escola uma atuação com vistas à superação de condições adversas ao desenvolvimento de uma educação de qualidade, ou seja, centrada na organização e desenvolvimento de ensino que promova a aprendizagem significativa à formação do aluno: pessoal, social e para o mundo do trabalho.

Nesta Resolução a atuação do diretor escolar deve se desenvolver em quatro dimensões da gestão, sendo elas: Pedagógica; de Pessoas; de Recursos Didáticos, Materiais, Físicos e Financeiros e de Resultados Educacionais do Ensino e Aprendizagem.

Apesar de ambas as Resoluções citadas acima contemplarem, em seus textos, preocupações com o processo educativo da escola e com "resultados educacionais do ensino e da aprendizagem", os diretores pesquisados ainda apresentaram visões bastante heterogêneas sobre sua função. Sem uma percepção clara e definida com relação à função que exercem, suas concepções parecem demonstrar falta de clareza acerca de seu papel. Percebe-se, também, a falta de objetividade e de compreensão da própria Secretaria Estadual de Educação de São Paulo (SEE/SP) quanto à expectativa acerca do trabalho do diretor, diante da complexidade e dos problemas que hoje caracterizam o cotidiano escolar.

\section{DIFICULDADES ENFRENTADAS PELOS DIRETORES NO DESEMPENHO DA SUA AÇÃO}

Com o intuito de melhor compreender a realidade dos diretores, identificamos, a partir de sua visão, as maiores dificuldades que encontram no desempenho de sua ação.

Apresentados como a maior dificuldade o "despreparo e a má formação dos professores e profissionais da escola" compareceram em $25 \%$ das respostas. Em seguida, com 18,7\%, outra grande dificuldade mencionada foi a "sobrecarga de trabalho", como relata o Sujeito 11: "A complexidade das funcões e as cobranças acumuladas pelos diversos setores e órgãos que não trabalham com um planejamento estratégico e o trabalho coletivo, sobrecarregando o papel do diretor." Praticamente com o mesmo índice, a categoria "pais/famílias ausentes no âmbito escolar", com 17,1\%, apresenta-se como outra dificuldade, indicando a ausência de participação e envolvimento da família na vida escolar dos filhos, conforme explicita o sujeito 3: "Os principais obstáculos que encontramos são: [...] pouca participação dos pais."

As demais categorias que abordam as dificuldades dos diretores foram: políticas públicas e legislação $(9,3 \%)$, ausência de professores e funcionários $(8,2 \%)$, indisciplina e desinteresse por parte dos alunos $(7,8 \%)$, necessidade de estimular a todos na escola $(4,6 \%)$, aprendizagem dos alunos $(3,1 \%)$, rotatividade 
dos professores $(3,1 \%)$, pouco espaço físico $(1,5 \%)$ e ausência do aluno ideal $(1,5 \%)$.

Portanto, podemos afirmar que, dentre as adversidades enfrentadas no exercício da direção escolar, sobressaem-se o despreparo e a má formação dos docentes, a predominância da sobrecarga de trabalho e a ausência dos pais e da família. Todos esses fatores, presentes na fala dos diretores investigados, já foram observados por outras pesquisas que abordam a participação dos pais no processo de tomada de decisões no interior da escola, no sentido de sua democratização (GARCIA; CORRÊEA, 2009; PARO, 2003; 2007). Outros estudos (GATTI; BARRETO, 2009; GATTI; BARRETO; ANDRÉ, 2011) também identificaram problemas em torno da formação inicial de professores e apontam que uma formação adequada pode contribuir para melhorar a qualidade da escola pública.

\section{CONCEPÇÃO DOS DIRETORES SOBE A GESTÃO DEMOCRÁTICA}

Em relação à tomada de decisões no interior da escola, 77,1\% dos diretores afirmaram que esse processo ocorre de modo coletivo. A predominância dessa afirmação, inicialmente, sugere a presença de uma gestão democráticoparticipativa que

[...] baseia-se na relação orgânica entre a direção e a participação dos membros da equipe. Acentua a importância da busca de objetivos comuns assumidos por todos. Defende uma forma coletiva de tomada de decisões. Entretanto, uma vez tomadas às decisões coletivamente, advoga que cada membro da equipe assuma sua parte no trabalho, admitindo a coordenação e a avaliação sistemática da operacionalização das deliberações (LIBÂNEO; OLIVEIRA; TOSCHI, 2012, p. 447).

Entretanto, numa análise mais acurada das respostas, percebe-se que, ao utilizarem-se do termo "coletivo", os 77,1\% diretores que enfatizaram a coletividade no processo de tomada de decisão na escola em que atuam não o fazem com a mesma compreensão.

Desses, 25,9\% usam o termo "coletivo" para se referir à equipe gestora e aos professores da escola. Para exemplificar esta visão, recorremos à fala de um dos diretores: "O processo de decisões sempre é a de diálogo do grupo gestor e troca de informações com professores em HTPC" (Sujeito 29).

Outros 25,9\% dos diretores empregam "coletivo" para se referir aos órgãos colegiados que existem na escola, tais como Conselho de Escola, Associação de Pais e Mestres (APM), Grêmio Estudantil, a equipe gestora e 
até mesmo a parceria desses colegiados com o Conselho Tutelar, Supervisor de Ensino da escola e Dirigente de Ensino. O sujeito 34 expressa o posicionamento desse grupo: “Através dos órgãos colegiados (Conselho de Escola, APM) sempre obedecendo à legislação vigente, respeitando a vontade da maioria dos membros dos respectivos órgãos ou segmentos de escola".

Tivemos 25,9\% diretores que, embora citem o "coletivo", não mencionam quais sujeitos estão envolvidos nesse processo. Destaca-se como exemplo dessa concepção a fala do Sujeito 26 que ressalta: "As decisões são tomadas no coletivo".

O termo "coletivo", num sentido mais amplo e sintonizado com o princípio da gestão democrática, envolvendo a equipe gestora da escola, professores, funcionários, alunos e pais, foi registrado por apenas 18,5\% dos diretores. Ao se referir como são tomadas as decisões na escola, um diretor respondeu "Nos vários grupos que existem na escola, professores, funcionários de apoio, gestores, pais e alunos" (Sujeito 32).

Vale destacar que $17,1 \%$ do total dos diretores ressaltam que as decisões são tomadas preferencialmente no coletivo, mas que às vezes o diretor precisa decidir sozinho ou em conjunto com a equipe gestora da escola. Isso ocorre em virtude da ausência de tempo para consultar o coletivo ou dependendo da necessidade como, por exemplo, em questões administrativas. A fala do Sujeito 20 expressa esse posicionamento: "Deveria ser um processo, mas as coisas e situações são tão adversas que nem sempre passa por um processo, elas ocorrem de forma imediatista, para ontem".

Paro (2011, p. 59), identifica a mesma prática em seu estudo e cita o depoimento de uma coordenadora pedagógica, que afirma que "talvez até em função da própria correria, a gente [...] A nossa mania, o nosso jeito é resolver tudo rapidinho, 'correndinho', e as coisas vão ficando, não se resolve, não se chama para conversar".

Acreditamos que os diretores das escolas públicas estaduais pesquisadas demonstram uma preocupação com a gestão democrática, mesmo que a compreensão ou a concretização do trabalho coletivo seja um grande desafio. Pois, a

[...] coordenação do esforço de funcionários, professores, pessoal técnicopedagógico, alunos e pais fundamentada na participação coletiva, é de extrema relevância na instalação de uma administração democrática no interior da escola. É através dela que são fornecidas as melhores condições para que os diversos setores participem efetivamente da tomada de decisões, já que estas não concentram mais nas mãos de uma única pessoa, mas de grupos ou de equipes representativos de todos [...]. (PARO, 1988, apud LIBÂNEO, 2001, p. 224). 
Segundo Sousa e Corrêa (2002, p. 57), apesar da gestão democrática está consagrada como princípio constitucional desde a Carta Magna de 1988 e comparecer também na LDB/96, "[...] essa determinação legal, por si só, não garante uma escola de qualidade e democrática. Esse fato mostra a necessidade de serem empreendidos esforços para a construção de uma escola realmente democrática”.

Embora a maioria dos diretores $(77,1 \%)$ reafirme a importância da gestão democrática, uma vez que destacam as decisões da escola em nível coletivo, é possível inferir que não existe consenso quanto ao processo de participação nestas decisões que se reflete nos diferentes posicionamentos sobre o significado das decisões tomadas "coletivamente".

Para compreender as dificuldades em implementar a participação democrática nas escolas públicas, indagamos os diretores sobre quais ações poderiam realizar na sua função de diretor para garantir a gestão democrática na sua instituição de ensino e obtivemos 56 respostas. As categorias com maior percentual foram "garantir participação e parcerias" (21,4\%); “incentivar a relação comunidade e escola" (17,9\%); "ouvir todos os segmentos da escola para a tomada de decisões" (17,9\%); "proporcionar mais autonomia a direção nas questões administrativas" (8,9\%); "ter formação continuada" (7,1\%); "qualificar e tornar os colegiados mais atuantes" (5,3\%); "trabalhar com professor para que tenham mais compromisso, além de conquistá-lo para um trabalho qualificado" (5,3\%); "unificar, na diferença, o trabalho da equipe gestora, avaliando ações e propondo mudanças" (3,6\%).

Vários diretores afirmaram que as categorias descritas acima exemplificam ações que já vêm sendo executadas nas escolas em que atuam.

Partilhar, ouvir, convidar a comunidade p/ participar mais. O que já acontece, mas não na quantidade de vezes que gostaria porque a gestão de tempo é um grande problema. Apesar dos convites/convocação, muitas vez̧es através de órgãos parceiros. Alguns pais não participam da vida escolar de seus filhos. Tem parceria c/ a Promotoria Pública que muito nos tem auxiliado. Preciso de mais tempo livre c/ todos os profissionais da U.E. p/ que o trab. democrático seja feito verdadeiramente (Sujeito 4).

Proporcionar momentos de discussões, estudo de caso e meio, levantamento de ações para os vários segmentos da escola - comunidade, professores, alunos e funcionários. Organizar os dados levantados e delegar funções e ajudar a definir prioridades (Sujeito 12).

A categoria "garantir participação e parcerias" obteve o maior percentual. Mas como garantir participação? O que entendemos como parceria? Para Libâneo, Oliveira e Toschi (2012), a participação das famílias pode ocorrer de modo informal, no contato dos pais com os professores do filho para 
acompanhamento do desempenho escolar, e também, de modo formal por meio da Associação de Pais e Mestres e no Conselho de Escola. Reforçando essa ideia de participação, Orsolon (2009, p. 178) afirma que

\footnotetext{
A participação dos pais na escola pode ocorrer, no âmbito individual, no sentido de buscar e receber orientações sobre a caminhada escolar do filho; e, no âmbito coletivo, quando eles podem contribuir com a gestão da escola, como membros do conselho escolar, da associação de pais e mestres ou de outro canal de participação previsto no projeto político pedagógico.
}

Mas, para que a participação dos pais possa acontecer, é preciso primeiro que haja a abertura de espaços dentro da escola.

Uma participação que ultrapasse o âmbito individual e atinja o âmbito coletivo constitui-se um desafio, visto que a escola tem aberto espaço de participação, mediante a gestão democrática assegurada pela LDB/96 nos órgãos colegiados, mas para uma "comunidade que ainda não está habituada à prática participativa" (ORSOLON, 2009, p. 178).

A segunda categoria mencionada refere-se a "incentivar a relação comunidade e escola", uma ação complexa, mas presente na LDB/96, principalmente no artigo 12, inciso VI onde consta "articular-se com as famílias e a comunidade, criando processos de integração da sociedade com a escola" como uma das incumbências das instituições de ensino.

Sabe-se que a articulação escola-família, quando realizada de forma efetiva, tem representado um fator determinante no sucesso do processo educativo. Deste modo, é positivo que a LDB/96 acene para o fortalecimento da participação dos usuários na gestão escolar. É preciso, entretanto, estar atento para não se confundir participação nas decisões com participação somente na execução/colaboração financeira (PARO, 1997).

A valorização da gestão democrática pela maioria dos diretores da DE/ PP, mesmo reconhecendo o enorme desafio que sua materialização representa em sua atuação profissional e no cotidiano da escola pública, é algo extremamente alentador, uma vez que o modelo de gestão escolar que ainda predomina em boa parte das escolas públicas brasileiras é o técnico-científico ou burocrático.

\section{AÇÃO DE FORMAÇÃO CONTINUADA}

A partir da discussão dos dados empíricos, que se constituíram das representações dos diretores da DE/PP sobre seu papel e as dificuldades enfrentadas no exercício de sua função, iniciamos as ações de formação continuada que tiveram como ponto de partida as próprias necessidades/ 
dificuldades indicadas, através de uma reflexão coletiva acerca da realidade vivenciada pelos sujeitos. É importante ressaltar que foram priorizadas as questões relacionadas à sua função e às complexidades no desempenho de seu ofício.

Gradativamente, a equipe se constituiu pelos sujeitos que aceitaram participar da ação de formação continuada fundamentada na pesquisa ação colaborativa, sendo composta, ao final da pesquisas em dezembro de 2014, por vinte e cinco diretores da $\mathrm{DE} / \mathrm{PP}$, três membros da $\mathrm{DE} / \mathrm{PP}$, cinco professores universitários e quatro alunos de pós-graduação.

Consideramos a formação continuada como o conjunto de atividades desenvolvidas pelos professores ou outros profissionais da educação, “[...] em exercício, com objetivo formativo, realizadas individualmente ou em grupo, visando tanto ao desenvolvimento pessoal como ao profissional", preparandoos para a realização de seus afazeres atuais ou de outros novos que se coloquem (ALMEIDA, 2005, p. 12). Para Libâneo (2001, p. 198), consiste no prolongamento da formação inicial e visa ao "[...] aperfeiçoamento profissional teórico e prático no próprio contexto de trabalho, e ao desenvolvimento de uma cultura geral mais ampla". Compreendemos, portanto, a formação continuada como possibilidade de proporcionar aos profissionais da educação, no caso desta pesquisa os diretores, um processo constante do aprender a profissão, não como resultado do acúmulo de informações, mas como um momento de repensar as suas práticas e construir novos conhecimentos que se constituem por meio do estudo, da reflexão, da discussão e da confrontação de diferentes experiências profissionais. Ao longo do percurso dos gestores na profissão, pudemos refletir, aprender, desaprender, reestruturar o aprendido, fazer descobertas, testar hipóteses, elaborar novas práticas e reconstruir seus saberes. (LIMA, 2013).

A ação de formação continuada apresentada neste texto resulta da parceria entre a universidade e a rede pública de ensino e se fundamenta numa perspectiva crítica reflexiva que tem como objeto de análise e discussão a identificação, pelos próprios participantes, das dificuldades e problemas de sua prática, iluminada pela qualificação teórica, enfatizando um processo de açãoreflexão-ação que visa propiciar o parecer crítico dos desafios, a reflexão sobre o campo de possibilidades em que se insere a prática do diretor, com destaque para a gestão democrática e a elaboração de um plano de ação para o enfrentamento e a superação dos desafios diagnosticados.

Em relação à dinâmica da formação continuada, realizamos catorze encontros que ocorreram mensalmente, com quatro horas de duração cada. Esses encontros apresentavam uma pauta constituída por uma epígrafe, tema a ser discutido, objetivo do encontro, informes gerais, realização da atividade 
do dia, café socializador e trabalho em grupo. Demandava também o registro escrito individual do encontro, sua avaliação e a identificação de diretrizes para a preparação do próximo. Em alguns deles, organizamos atividades para os diretores desenvolverem na escola em que atuam, as quais, no encontro seguinte, eram apresentadas, por escrito e oralmente. De acordo com Libâneo (2001, p. 190),

[...] não basta saber sobre as dificuldades da profissão, é preciso refletir sobre elas e buscar soluções, de preferência, mediante ações coletivas. Segundo Philippe Perrenoud, a reflexão possibilita transformar o mal-estar, a revolta, o desânimo, em problemas, os quais podem ser diagnosticados, explicados e até resolvidos com mais consciência, com mais método. Ou seja, uma prática reflexiva [...] leva a uma relação ativa e não queixosa com os problemas e dificuldades.

Importante salientar que os rumos/temas/conteúdos da ação de formação continuada foram construídos gradativamente, conforme o avanço dos encontros, por meio dos estudos teórico-reflexivos, da manifestação acalorada dos presentes e da rica e necessária troca de experiências entre os sujeitos. O interesse do grupo de diretores pela proposta de formação continuada em curso é atestado pela assiduidade e intensa participação de tais profissionais nos encontros desenvolvidos.

Após cada reunião, realizávamos uma avaliação no grupo de coordenação do projeto, composto pela equipe de professores e alunos da Faculdade de Ciências e Tecnologia da Universidade Estadual Paulista (UNESP) e pelo Grupo de Referência da DE/PP (membros da DE/PP e dois representantes dos diretores). Também organizávamos o próximo compromisso a partir das necessidades dos diretores expressas pela avaliação do dia e pelas sugestões dadas.

Ancorados na proposta da pesquisa ação colaborativa e considerando as necessidades formativas dos diretores, desenvolvemos a ação de formação continuada. A partir dos registros escritos, é possível constatar que estes a avaliam positivamente, bem como valorizam tal espaço de formação profissional, conforme trechos descritos abaixo:

O encontro foi muito proveitoso, pois veio refletir a nossa gestão, contribuindo para pensarmos nas reais possibilidades de mudanças a fim de tornar realidade a gestão democrática. (Sujeito 21-10/5/13).

Toda reunião tem um objetivo; encontramos caminhos e soluções para nossos problemas. A luta é pelo nosso aluno, os problemas são comuns a todos. (Sujeito 1-20/9/13).

A reunião foi muito produtiva e conduحida com bastante tranqüilidade. O grupo trabalhou temas que trouxe da escola e que angustia toda a equipe e iniciou-se o trabalbo de se discutir a solucões. Ficou claro que apenas iniciamos o trabalbo e muito bá que se pensar. (Sujeito 9-20/9/13). 
Estes relatos demonstram diferentes dimensões do trabalho realizado, com destaque para o envolvimento dos diretores no sentido de uma reflexão e construção coletiva que partiu da análise dos problemas enfrentados no cotidiano de suas escolas e que, por essa razão, foram capazes de gerar forte identificação com os pontos levantados nas discussões. Demonstram, ainda, que estes profissionais se compreendem como sujeitos que têm experiências, saberes e práticas, bem como se percebem como agentes de sua própria formação e sujeitos que podem contribuir para a transformação da realidade escolar na qual estão inseridos.

No final de 2013, realizamos uma avaliação sobre a ação de formação continuada, cujos resultados apresentamos na Tabela 1 abaixo.

\section{Tabela 1 - Avaliação dos participantes sobre a formação continuada vivenciada}

\begin{tabular}{|l|c|c|}
\hline \multicolumn{1}{|c|}{ CATEGORIAS } & Freq. & \% \\
\hline $\begin{array}{l}\text { Sinto me fortalecido e mais seguro como grupo e indivíduo com } \\
\text { as discussões e trocas de experiências para desenvolver uma gestão } \\
\text { democrática, além de constatar que nossas dificuldades do cotidiano } \\
\text { da escola são semelhantes. }\end{array}$ & 9 & 36 \\
\hline $\begin{array}{l}\text { Desenvolvi a prática da reflexão que proporciona um novo olhar } \\
\text { sobre o meu trabalho e minha percepção como gestor que foi alterada, } \\
\text { ampliada e melhorada. }\end{array}$ & 5 & 20 \\
\hline Busco trabalhar de forma mais democrática. & 3 & 12 \\
\hline Busco desenvolver na escola as ideias discutidas na reunião. & 2 & 8 \\
\hline $\begin{array}{l}\text { Aprendi a ter visão crítica, solução de problemas e necessidades de } \\
\text { mudanças nas estratégias de ensino. }\end{array}$ & 2 & 8 \\
\hline $\begin{array}{l}\text { Tenho desenvolvido intervenções adequadas e sábias a partir da } \\
\text { observação dos professores e da liderança desse grupo. }\end{array}$ & 1 & 4 \\
\hline $\begin{array}{l}\text { Vislumbro algumas alternativas para superar as dificuldades, como: } \\
\text { possibilidade de dividir as tarefas com os diferentes segmentos da } \\
\text { escola. }\end{array}$ & 1 & 4 \\
\hline $\begin{array}{l}\text { Melhorei algumas ações do dia a dia como: fazer um diário de bordo; } \\
\text { organizar uma agenda; estudar a LDB e Regimento; relacionamentos. }\end{array}$ & 1 & 4 \\
\hline $\begin{array}{l}\text { Tenho procurado “encontrar tempo" para leituras complementares, } \\
\text { participação em outros cursos relacionados à gestão pública. }\end{array}$ & 1 & 4 \\
\hline TOTAL & 25 & 100 \\
\hline
\end{tabular}

Fonte: Pesquisa realizada, 2013. 
Nota-se que a experiência vivenciada pelos diretores foi significativa e relevante como um espaço de formação continuada desses profissionais. Dentre os catorze diretores que participaram da avaliação dos trabalhos, nove afirmaram que se sentiam fortalecidos e mais seguros com as discussões para desenvolverem uma gestão democrática nas escolas em que atuam. Outros valorizaram a prática da reflexão e a possibilidade de buscar novas formas para se trabalhar coletivamente. Os depoimentos abaixo comprovam essa análise:

\begin{abstract}
Apesar de tantos anos de experiência na direção de repente me deparei com a realidade que até então pouco havia refletido sobre o cotidiano da escola. Acostumada com o excesso de trabalho burocrático, não priorizava a reflexão sobre os acontecimentos que interferem no dia-a-dia. Para mim a grande mudança na postura foi comecar a desenvolver a prática da reflexão, pensar no porquê? O Que devo ou posso fazer? Até que ponto a minha postura, posição contribui para ocorrência deste ou não? Hoje fico pensando o quanto estive e estou aberta as mudanças. O quanto tenho facilitado ou contribuindo? Enfim, considero valiosos esses momentos, pois, proporcionam um novo olbar sobre mim e minha prática e que esse novo posicionamento, possa tornar efetiva as mudanças que faz̧em necessárias para uma educação melhor. (Sujeito 13-29/11/13).
\end{abstract}

No decorrer do ano sai de alguns encontros "sem chão", mas refletindo, como encontrar alternativas para superar as dificuldades. [...] Entendi que devo ouvir a todos, individualmente ou coletivamente, para que juntos possamos vivenciar os fracassos e sucessos da escola em todos os aspectos e mostrar a equipe escola essa necessidade de trabalho coletivo. Com os colegas diretores dividimos as angustias do cargo, mas também tentamos amenizar com outras experiências e sugestões, as quais foram muito importantes. (Sujeito 5 - 29/11/13).

\title{
CONSIDERAÇÕES FINAIS
}

Este pesquisa relata uma experiência de formação continuada de diretores, fundamentada na pesquisa ação colaborativa que teve início em 2012 junto à DE/PP.

A opção metodológica pela pesquisa ação colaborativa fundamentou-se na possibilidade de se criar um espaço permanente de investigação, reflexão e análise das práticas profissionais no interior das escolas, efetuadas pelos diretores em parceria com a universidade. Pensamos que os diretores devem ser autores de sua ação, planejando-a, refletindo acerca de seus problemas e recriando uma nova conduta, pois nenhuma experiência pode se definir como uma mera execução. $\mathrm{O}$ aspecto formativo dessa metodologia de pesquisa evidencia que este procedimento exige uma relação com os sujeitos da prática, o que implica coparticipação, coautoria e coprodução de conhecimentos e saberes.

Os profissionais da educação - nesta pesquisa, os diretores - não mudam a partir de simples resolução da Secretaria de Educação do Estado. A mudança ocorre em virtude de alterações nas concepções e valores que podem refletir em 
suas atitudes e comportamentos, por meio da tomada de consciência sobre a necessidade e a possibilidade de novas proposições. Essa mudança individual pode conduzir a um sentimento de fortalecimento e de segurança quando socializada, discutida, refletida e decidida com o grupo, através da reflexão crítica acerca das dificuldades no exercício de seu papel na escola.

Enfim, percebemos que os diretores constroem novos significados para a sua atuação por meio da reflexão de sua prática, articulada com a teoria, compartilhada com o coletivo e tendo o desejo de melhorar a própria atuação profissional. Reafirma-se, ainda, que desenvolver projetos de pesquisa-ação mostrou-se uma estratégia importante para desencadear mudanças nas práticas dos diretores e nas ações de formação continuada, caracterizando-se como um verdadeiro processo de desenvolvimento profissional (LEITE, 2014).

As atividades realizadas, fundamentadas na reflexão-ação-reflexão, proporcionaram aos diretores maior clareza da importância de seu papel dentro da unidade escolar, além da necessidade de entender e refletir sobre as dificuldades encontradas para melhor conduzir a escola que dirigem, propiciando a toda equipe que a integra possibilidades de mudanças necessárias para assegurar a gestão democrática.

\section{REFERÊNCIAS}

ALMEIDA, M. I. Formação contínua de professores em face das múltiplas possibilidades e dos inúmeros parceiros existentes hoje. In: ALMEIDA, M. I. (Org.). Formação Contínua de Professores. Brasilia: Ministério da Educação, boletim 13, ago. 2005. p. 11-17.

ASSUNÇÃO, M. M. Magistério primário e cotidiano escolar. Campinas: Autores Associados, 1996. 96 p.

BRASIL. Constituição da República Federativa do Brasil. Brasília: Senado Federal, 1988. Disponível em: <http://www.planalto.gov.br/ccivil_03/ constituicao/constituicaocompilado.htm >. Acesso em: 20 jan. 2013.

. Lei $\mathbf{n}^{\circ}$ 9.394, de 20 de dezembro de 1996. Estabelece as Diretrizes e Bases da Educação Nacional. Disponivel em: <http://www.presidencia.gov.br/ legislacao/>. Acesso em: 20 out. 2012.

CARVALHO, M. P. No coração da sala de aula: gênero e trabalho docente nas séries iniciais. São Paulo: Xamã, 1999. 248 p. 
DAVIS, C.; GROSBAUM, M. W. Sucesso de todos, compromisso da escola. In: DAVIS, Claudia. (et al). Gestão da escola: desafios a enfrentar. Rio de Janeiro: DP\&A, 2002.p. 77-112.

FRANCO, M. L. P. Análise de Conteúdo. Brasília: Líber Livro, 2008. 80 p.

GARCIA, T. O.; CORREA, B. C. Desafios à democratização da gestão escolar e a atuação dos professores na escola pública. Revista Retratos da Escola, Brasília, v. 3, n. 4, p. 225-237, jan./jun. 2009.

GATTI, B. A.; BARRETO, E. de S. (Coord.). Professores do Brasil: impasses e desafios. Brasília: UNESCO, 2009.

GATTI, B. A.; BARreto, E. de S.; ANDrÉ, M. E. D. A. Políticas docentes no Brasil: um estado da arte. Brasília: UNESCO, 2011.

LIMA, V. M. M. Necessidades formativas docentes como subsídios para uma política de formação contínua em serviço. In: LEITE, Y.U.F.; MILITÃO, S.C.N; LIMA, Vanda Moreira Machado (Orgs). Políticas Educacionais e qualidade da escola pública. 1.ed. Curitiba, PR: CRV, 2013.p. 127-154.

LEITE, Y. U. F. Pesquisa ação como espaço de formação de professores: análise de uma experiência vivida. In: PIMENTA, S. G.; FRANCO, M. A. S. Pesquisa em educação: possibilidades investigativas, formativas da pesquisa ação. 2. ed. São Paulo: Edições Loyola, 2014. v. 2. p. 95-112.

LIBÂNEO, J. C. Organização e Gestão da Escola: teoria e prática. Goiânia: Editora Alternativa, 2001. 260 p.

LIBÂNEO, J. C.; OLIVEIRA, J. F.; TOSCHI, M. S. Educação Escolar: políticas, estrutura e organização. 10.ed. ver.ampl.São Paulo: Cortez, 2012.

ORSOLON, L. A. M. Trabalhar com as famílias: uma das tarefas da coordenação. In: PLACCO, V. M. N. S., ALMEIDA, L. R.. (Orgs.). O coordenador pedagógico e o cotidiano da escola. 6. ed. São Paulo: Edições Loyola, 2009, p. 177-183.

PARO, V. H.. Crítica da estrutura da escola. São Paulo: Cortez. 2011.

Qualidade do ensino: a contribuição dos pais. São Paulo: Xamã, 2007.

. Eleição de diretores: a escola pública experimenta a democracia. São Paulo: Xamã, 2003.

Gestão democrática da escola pública. São Paulo: Ática, 1997. 
PIMENTA, S. G. Professor reflexivo: construindo uma crítica. In: PIMENTA, S. G.; GHEDIN, E. (Org.). Professor reflexivo no Brasil - gênese e crítica de um conceito. São Paulo: Cortez, 2002. p. 17-52.

PIMENTA, S. G. Pesquisa-ação-colaborativa: construindo seu significado a partir de experiências com a formação docente. Educação e Pesquisa, São Paulo, v. 31, n. 3, p. 521-539, set./dez. 2005.

RIBEIRO, J. Q. Introdução à administração escolar. In: TEIXEIRA, A. S.; RIBEIRO, J. Q.; BREJON. M.; MASCARO, C. C. Administração Escolar. Salvador: ANPAE, 1968.

SÃO PAULO (Estado). Secretaria da Educação do Estado de São Paulo. Resolução SE no 52, de 14 de agosto de 2013. Dispõe sobre os perfis, competências e habilidades requeridos dos Profissionais da Educação da rede pública estadual, os referenciais bibliográficos e de legislação, que fundamental e orientam a organização de exames, concursos e processos seletivos, e dá providências correlatas. Disponível em: http://www.educacao.sp.gov.br/cgrh/ wp-content/uploads/2014/06/RESOLU $\%$ C3\%87\%C3\%83O-SE-52-de-14-82013-PERFIS-PARA-CONCURSO.pdf. Acesso em: 20 jan. 2014.

SÃO PAULO (Estado). Secretaria da Educação do Estado de São Paulo. Resolução SE $n^{\circ} 70$, de 26 de outubro de 2010. Dispõe sobre os perfis profissionais, competências e habilidades requeridos dos educadores da rede pública estadual e os referenciais bibliográficos que fundamentam os exames, concursos e processos seletivos, e dá providências correlatas. Disponível em: http://siau. edunet.sp.gov.br/ItemLise/arquivos/RESOLU $\%$ C3\%87\%C3\%83O $\% 20 \mathrm{SE} \% 20$ N\%C2\%BA\%2070_10.HTM. Acesso em: 10 fev. 2013.

SILVA JUNIOR, C. A. da. A escola pública como local de trabalho. São Paulo: Cortez; Autores Associados, 1990.

SOUSA, J.V; CORRÊA, J. Projeto Pedagógico: a autonomia construída no cotidiano da escola. In: DAVIS, C. (et al). Gestão da escola: desafios a enfrentar. Rio de Janeiro: DP\&A, 2002.p. 47-75.

TANURI, L. M. História da formação de professores. Revista Brasileira de Educação: 500 anos de educação escolar, Rio de Janeiro, n. 14, p. 61-88, mai./ jun./jul./ago. 2000. Número Especial. 
YOSHIE USSAMI FERRARI LEITE é doutora em Educação pela Universidade Estadual de Campinas, com estágio de pós-doutoramento em Educação na Universidade de São Paulo. É professora Livre-docente da FCT/Unesp/ Campus de Presidente Prudente, onde atua no Departamento de Educação e no Programa de Pós-graduação em Educação. E-mail: yoshie@fct.unesp.br

VANDA MOREIRA MACHADO LIMA é doutora pela USP/São Paulo e professora assistente doutor do Departamento de Educação da FCT/UNESP Campus de Presidente Prudente. E-mail:vandalima@fct.unesp.br

Recebido em fevereiro de 2015

Aprovado em março de 2015 